\title{
Non-insured Health Benefits for First Nations and Inuit People: an Overview for Information Providers
}

\author{
Jessie Loyer and Marija Small Legs
}

The Non-insured Health Benefits (NIHB) program provides First Nations and Inuit people in Canada with coverage for a limited range of medically necessary goods and services. These can include prescription drugs, dental care, vision care, medical supplies and equipment, shortterm crisis counselling, and medical transportation [1]. This article provides health librarians and other providers of consumer health information with some background on the program, differing perspectives on the legal and treaty requirements for service provision, the health literacy implications, and the role of a Treaty 7 NIHB Navigator in service delivery.

\section{Background and perspectives on the provision of NHIB}

Health care has been perceived in vastly different ways by government and First Nations people. Government support of medical services for First Nations, Inuit, and Métis people has a long history and various departments have been responsible over the years. The Medical Services Branch of Health Canada (MSB) was created in 1962 when various field services were merged with the Indian Health and Northern Health Services. MSB was renamed the First Nations and Inuit Health Branch in 2000 and now administers NIHB [2].

The federal government claims the NIHB program supports registered First Nations and recognized Inuit in reaching an overall health status comparable to other Canadians. Though their health status is not equal and comparable, First Nations and Inuit people continuously work to ensure their health needs are met and are equal to other Canadians, and they assert that health benefits are an inherent Aboriginal and Treaty right and are constitutionally protected [3].

In 1974, the federal government's position was written in a policy that stated there were no statutory or treaty obligations for providing health services to Indians, though the federal government would provide services and give financial assistance when medically necessary [2]. They had also previously noted in 1957 that under Treaty Six medical care was an obligation, but medical services for all Indians were provided on humanitarian rather than on legal grounds [4]. This difference in perspective creates barriers and jurisdictional issues around access to health care for First Nations and Inuit people.

Treaty $\mathrm{Six}$ is the only treaty that specifically mentions health care in its text, which includes the clause for a medicine chest to be held at the Indian agent's home and offers emergency help, for example during epidemics. These clauses have been interpreted in various ways, particularly around the extent of care [4]. However, the Supreme Court affirmed that the terms of treaties are not limited to the text in the treaty, but rather include the actual agreements between the parties [3]. Historical documents show that several other treaty negotiations included discussions about the provision of medical services, but those discussions did not appear in the final text of the treaty [4].

In addition to these specific clauses in Treaty Six, there are other supporting arguments around treaty rights and health care. Historical events support the First Nations assertion that medical care was tied to treaty rights. The connection between treaty and health care was solidly entrenched, with doctors frequently in attendance when treaty annuities were paid out, so much so that people at York Factory in Treaty Five spoke out in anger when no doctor accompanied the annuity treaty payments of $\$ 5$ in 1915 [4].

From a First Nations historical perspective, disagreements over jurisdiction and responsibility for the delivery of medical services influence current obstacles to access for First Nations and Inuit patients. These obstacles can include funding for the NIHB program, effective communication, limited transportation, and in many cases, limited access to provincial health services and programs if clients reside on reserve. When the Assembly of First Nations (AFN) assessed the NIHB program in 2005, they found that increases in funding levels were only limited to an estimated population growth rate. Health needs and cost drivers were not considered as part of the funding equation [3]. As well, cutbacks in the 1990s confused clients as benefits were delisted, eligibility and access changed, and generic drugs were encouraged; these changes continue today. Before certain medications could be accessed at a

Jessie Loyer ${ }^{1}$. Indigenous Studies Library, Mount Royal University, 4825 Mount Royal Gate SW, Calgary AB T2E 6K6. Marija Small Legs. Treaty 7 Management Corporation Health Secretariat, \#101 1211140 Street SE, Calgary AB T2Z 4E6.

${ }^{1}$ Corresponding author (e-mail: jloyer@mtroyal.ca). 
pharmacy, Health Canada demanded that doctors and other health care providers submit their services for prior approval and predetermination for many drugs and for dental services, which complicated the process [3]. These processes are still complicated today through predetermination, which is a process of prior approval where health care providers must submit cases to Health Canada for review; prior approval is time consuming and is required to access all vision care, transportation, and counselling, most dental, medical supplies and equipment benefits, and for some drug benefits [1].

Unlike private health care plans, NIHB has many limitations and barriers to accessing services; funding to these services decreases yearly, which limits coverage. The NIHB processes currently in place are time consuming, financially draining, and often the ultimate result will be a denial. Providers are often unwilling to work with the burdensome NIHB process. Health Canada considers itself the Payer of Last Resort, and state that "where a benefit is covered under another plan" they promote that plan instead of providing health care coverage [1]. NIHB Navigators help to empower First Nations and Inuit clients to ensure that they can advocate to enhance their health care and to ensure their needs are met and that the care delievered is equal to that of other Canadians.

Access to NIHB is also limited by identity categorization. NIHB is one of the only federal programs for First Nations that extends beyond reserve borders. Any registered Indian and recognized Inuit person can access these benefits, regardless of where they live [6]. However, NIHB does not cover the health care of those not recognized by the Canadian federal government such as non-status Indians, non-recognized Inuit, or Métis people who do not have access to the same benefits thanks to these "historically produced categorizations of indigenous people" [6].

\section{Health literacy implications}

Confusion among clients over access and coverage has health literacy implications. In Canada, health literacy is defined as "the ability to access, understand, evaluate, and communicate information as a way to promote, maintain, and improve health in a variety of settings across the lifecourse" [7]. Health librarians working with First Nations and Inuit people should keep in mind that these clients may not be aware of all services available to them under the NIHB program.

For patients to access required medical services, they first need to be informed about the changes to their care. Information on changes to the NIHB program benefits is often not communicated in a clear and timely fashion, leaving First Nation and Inuit members uninformed until they access the service or care. Information about NHIB is often confusing, particularly for elders who are frequent users of medication, dental care, and ophthalmology services [6]. When asked about communication around health care by the National Aboriginal Health Organization, a sample of First Nations respondents felt that health information was not readily available, that it was difficult to access, and that there were large areas of health care services not represented well. Although this survey does not represent all First Nations in Canada, of those surveyed nearly $50 \%$ did not know how easy it was to access midwives, $20 \%$ did not know about the accessibility of mental health services, and $18 \%$ did not know about access to pediatricians, addictions workers, and social workers [8].

When surveyed about what would improve Aboriginal health, $85 \%$ of respondents cited the need for more information on health-related topics in their communities [8]. In another survey when asked about NIHB and Health Canada, communication strategies such as seminars, community education sessions, and regular info bulletins were identified as helpful strategies to navigate the complicated and time-consuming processes [3]. People overwhelmingly agreed that clear, culturally relevant information would not only help them navigate their health care, including NIHB, but also improve their overall health.

\section{The role of NIHB Navigators}

Because health benefits vary according to region, some regions may have more provincial and territorial support than others, and general resources describing the NIHB program may not fully answer clients' specific questions about their regional coverage; experts at the regional level are crucial to navigate issues, barriers, and obstacles. This expertise takes the form of NIHB Navigators such as Marija Small Legs, one of this article's authors, who works with First Nations and Inuit people in the Treaty 7 territory and Alberta region. NIHB Navigators support and provide assistance to eligible First Nations and Inuit clients in accessing the NIHB Program. The role of a Navigator is to support First Nation and Inuit communities in gaining an increased understanding of existing health services, jurisdictional issues, and the limitations of the NIHB program. The Navigator works to exchange, gather, and collate information on health access issues and denials of services. This data can be used to identify areas where health services can be improved for their clients. The NIHB Navigator can advocate on the behalf of their clients through the appeal process when a benefit has been denied and liaises with regional Health Canada staff to support their communities through this process.

In Alberta Treaty 6, Treaty 7, and Treaty 8 all have their own Navigators, but these Navigators work together to ensure they meet the needs of all Treaty First Nation and Inuit members regardless of jurisdiction. This enables the Navigator to strengthen relationships with health care providers, professionals such as pharmacists, and communities and to create and enhance partnerships. They also work to inform, educate, and provide information and support to those having difficulty accessing and navigating the policy, procedures, and the numerous administrative requirements of the NIHB program for accessing NIHB services or when dealing with NIHB providers.

First Nations and Inuit peoples face many challenges to their healthcare; some examples include transportation, access to prescription medicines that may be removed from the Drug Benefit List (DBL), and preauthorization criteria for some services. NIHB Navigators can assist patients with these obstacles and connect them to the services they require if they exist and no jurisdictional issues apply.

Many health services are not located on First Nation reserves. Individuals may have to commute great distances 
from their communities to obtain health care and services. Clients must coordinate with medical transportation to attend appointments outside of their community within specified timeframes; this can be quite burdensome and stressful for those who are ill and elderly and who may need to be transported in a van with other patients, regardless of the time their appointments are scheduled. If medical transportation is required after work hours many clients are left stranded without any way to return to their communities.

Prescription medications can often be unlisted or delisted from NIHB's DBL. A medication may be prescribed, but may not be available for access under the NIHB pharmacy plan. For example, a client may go to the pharmacy and be informed that the drug is not listed on the DBL, despite the fact that their medication may be essential for their care. Limited use prescribed medications may be considered for NIHB program coverage under special circumstances with prior approval. First Nations and Inuit clients must request that their pharmacist resubmit the claim if not approved and have the prior approval request reviewed by the NIHB Drug Exception Centre (DEC). Navigators encourage and advise First Nation members to inform pharmacies to contact DEC to determine if an exception can be made and have Health Canada provide the prescribed medication. When a request is denied, the NIHB Navigator may assist First Nations and Inuit clients to appeal unfavourable decisions if they so choose.

NIHB Navigators are excellent resources for building capacity around health literacy. Navigators also link First Nations and Inuit patients to the programs and services they can access and help them navigate a complicated system. To better serve their First Nations and Inuit users who may have difficulty accessing NIHB, libraries should make connections with the NIHB Navigators in their region.

\section{Further resources}

Complete information on the NIHB program, including regional offices, can be found on Health Canada's web site at: http://www.hc-sc.gc.ca/fniah-spnia/nihb-ssna/indexeng.php. Information about regional navigators can be found through Health Canada regional offices, First Nation regional offices, or AFN Caucus members.

\section{References}

1. Health Canada \& Assembly of First Nations. Your health benefits: a guide for First Nations to access non-insured health benefits. Alberta Region. Health Canada; 2013. 41 pp.

2. Health Canada. History of providing health services to First Nations people and Inuit [Internet]. Ottawa: Health Canada; 2010. [cited 24 January 2014]. Available from: http://www.hcsc.gc.ca/ahc-asc/branch-dirgen/fnihb-dgspni/services-eng.php.

3. Assembly of First Nations. First Nations action plan for non-insured health benefits. Ottawa, ON: Assembly of First Nations; 2005. 32 pp.

4. Waldram JB, Herring DA, Young TK. editors, editors. Aboriginal health in Canada: historical, cultural, and epidemiological perspectives. $2^{\text {nd }}$ ed. Toronto: University of Toronto Press; 2007. 367 pp.

5. Assembly of First Nations. First Nations action plan for noninsured health benefits. Ottawa: Assembly of First Nations; 2005. 32 pp.

6. deLeeuw S, Greenwood M. Beyond borders and boundaries: Addressing Indigenous health inequities in Canada through theories of social determinants of health and intersectionality. In Hankivsky O, editor, editor. Health inequalities in Canada: Intersectional frameworks and practices. Vancouver: UBC Press; 2011. 412 pp.

7. Rootman I, Gordon-El-Bihbety D. A vision for a health literate Canada: report of the Expert Panel on Health Literacy. Ottawa: Canadian Public Health Agency; 2008. 48 pp.

8. First Nations Centre, National Aboriginal Health Organization. What First Nations think about their health and health care: the National Aboriginal Health Organizations' public opinion poll on First Nations health and health care in Canada. Ottawa, ON: National Aboriginal Health Organization; 2004. 